\title{
REFERENCE EVAPOTRANSPIRATION FORECASTING BY ARTIFICIAL NEURAL NETWORKS
}

Doi:http://dx.doi.org/10.1590/1809-4430-Eng.Agric.v37n6p1116-1125/2017

\section{WALISON B. ALVES ${ }^{1}$, GLAUCO DE S. ROLIM"1, LUCAS E. DE O. APARECIDO2*}

\author{
${ }^{2 *}$ Corresponding author. São Paulo State University (Unesp), School of Agricultural and Veterinarian Sciences/ \\ Jaboticabal - SP, Brazil. E-mail: lucas-aparecido@outlook.com
}

\begin{abstract}
Evapotranspiration (ET) is the main component of water balance in agricultural systems and the most active variable of the hydrological cycle. In the literature, few studies have used the forecast the day before via Artificial Neural Networks (ANNs) for the northern region of São Paulo state, Brazil. Therefore, this aimed to predict the reference evapotranspiration for Jaboticabal, the major sugarcane-producing region of São Paulo state. We used a historical series of data on average air temperature, wind speed, net radiation, soil heat flux, and daily relative humidity from 2002 to 2012, for Jaboticabal, SP (Brazil). ET was estimated by Penman-Monteith method. To forecast reference evapotranspiration, we used a feed-forward Multi-Layer Perceptron (MLP), which is a traditional Artificial Neural Network. Numerous topologies and variations were tested between neurons in intermediate and outer layers until the most accurate were obtained. We separated $75 \%$ from data for network training (2002 to 2010) and 25\% for testing (2011 to 2013). The criteria for assessing the ANN performance were accuracy, precision, and trend. ET could be accurately estimated with a day to spare at any time of the year, by means of artificial neural networks, and using only air temperature data as an input variable.
\end{abstract}

KEY WORDS: modeling, Multi-Layer Perceptron, air temperature, estimate.

\section{INTRODUCTION}

Brazil climate patterns are widely diverse (Alvares et al., 2014). In the North region, there is a rainy equatorial climate without any dry season, while in the Northeast, the rainy season has low rainfall and is restricted to a few months, featuring a semi-arid climate and presenting high climate predictability. On the other hand, tropical systems and mid-latitudes influence Southeast and Midwest, which present a well-defined dry season (winter), and a rainy season (summer) with convective rainfall. Finally, the southern region of Brazil is characterized by medium predictability, and due to its latitudinal location, suffers more influence of mid-latitude systems, where frontal systems are the main causes of rainfall during the year (Sampaio \& Silva Dias, 2014).

Evapotranspiration (ET) is the main component of water balance in agricultural systems and the most active variable of the hydrological cycle (Dong \& Dai, 2016; Aparecido et al., 2017a). ET is a key parameter for watershed management studies (Raziei \& Pereira, 2013), for crop water requirement estimates and for irrigation project and management (Kumar et al., 2008). Weather conditions have marked influence on ET; subsequently, small mistakes in its estimate have a high impact on the water balance calculation for a region (Carvalho et al., 2015).

Reference evapotranspiration $\left(\mathrm{ET}_{0}\right)$ is measured by techniques and relatively complex physical principles (Allen et al., 2011), and the most direct and accurate way to estimate it is by water balance in the soil using lysimeters. However, due to limitations associated with the method, the adoption of physical mathematical models has become a practical alternative to ET estimation. From the results of numerous studies conducted in recent decades, the combined Equation of Penman Monteith (PM), modified by Allen et al. (1998), is the best to represent physical and physiological factors involved in the evapotranspiration process. The main disadvantage of this Equation is its large number of meteorological variables for operation. Therefore, once many weather stations do not have all the mandatory sensors, which, even when present, often provide

\footnotetext{
${ }^{1}$ São Paulo State University (Unesp), School of Agricultural and Veterinarian Sciences/ Jaboticabal - SP, Brazil. 
low-quality data. This a significant observation to be regarded, especially for developing countries where reliable sets of radiation, relative humidity, and wind speed data are not always available (Trajkovic \& Kolakovic, 2009).

Evapotranspiration knowledge is essential for activities related to watershed management in meteorological and hydrological modeling, mainly for water management in irrigated agriculture (Dutta et al., 2016). According to Back (2007), various water-balance models are embraced to scale irrigation systems and to study probabilities of drought or water excess occurrences. Regarding these models, the water entry into a system is made by precipitation and irrigation, and the main water outlet is driven through evapotranspiration.

In the delineation of land use classes, Artificial Neural Networks (ANNs) approach has shown significant results when compared to traditional methods of classification (Were et al., 2015). Kim et al. (1995) highlighted the robustness of an artificial intelligence system, which offers a great reference for discrimination of land cover classes if compared to conventional classification systems.

ANNs are computational models inspired by the biological nervous system, with a similar operation to some human procedures; in other words, it learns by experience, generalizes examples through others, and can abstract characteristics. The ability to learn through examples and generalize information learned is the main attraction of troubleshooting through ANNs (Nath et al., 2016). Generalization, which is associated with the network capacity to learn through a small set of examples giving consistent answers to unknown data, demonstrates the ANN's ability to go far beyond a simple mapping of input and output relations. ANNs are able to extract information not presented in explicit form through examples (Feng et al., 2015; Liu et al., 2015).

An estimate determines the current value based on historical data, while a forecast predicts a future value using the same historical data (Aparecido et al., 2017b). In the literature, estimates are more common than are forecasts. For example, Kumar et al. (2002) estimated ET 0 through ANNs for India using solar radiation, maximum and minimum temperatures, maximum and minimum relative humidity, and wind speed as inputs. In addition, Zanetti et al. (2007) estimated $\mathrm{ET}_{0}$ by Penman-Monteith, using ANNs for Campos dos Goytacazes, in Rio de Janeiro state.

Nonetheless, few studies performing $\mathrm{ET}_{0}$ forecasts were found in the literature, for example, Trajkovic et al. (2003), who forecasted $\mathrm{ET}_{0}$ via Penman-Monteith method in Serbia and Montenegro for a day in advance, using ANNs with air temperature, relative humidity, wind speed, and the sunshine as inputs. Results have proved ANNs can be applied for reference evapotranspiration forecasting, with high reliability. Moreover, Izadifar and Elshorbagy (2010) made evapotranspiration prediction on an hourly scale for one day in advance using neural networks and genetic algorithms. Lastly, accurate forecasting results were observed, and the weather elements with greater influence on ET were net radiation and soil temperature.

Since studies on evapotranspiration prediction with a day in advance by ANNs are scarce in the northern region of São Paulo state, the aim of this study was to perform reference evapotranspiration prediction for the region of Jaboticabal - SP (Brazil), which is a major sugarcane-producing region of the state.

\section{MATERIAL AND METHODS}

In this survey, we used historical series of data on average air temperature, wind speed, net radiation, soil heat flux, and daily relative humidity, which covered the period from 2002 to 2012 , for Jaboticabal, SP (Figure 1). Reference evapotranspiration was estimated by Penman-Monteith method (Equation 1).

$$
\text { ET0 }=\left(\frac{0.408 \times \Delta \times(R n-G)+\gamma \times\left(\frac{900}{T+273}\right) \times U 2 \times(e s-e)}{\Delta+\gamma \times(1+0.34 \times U 2)}\right)
$$

where, 
$\mathrm{ET}_{0}$ is the reference evapotranspiration;

$\mathrm{Rn}$ is net radiation $\left(\mathrm{MJ} \mathrm{m}^{-2} \mathrm{day}^{-1}\right)$;

$\mathrm{G}$ is soil heat flux $\left(\mathrm{MJ} \mathrm{m}^{-2} \mathrm{day}^{-1}\right)$;

$\mathrm{U} 2$ is wind speed $\left(2 \mathrm{~m} \mathrm{~s}^{-1}\right)$;

$\mathrm{g}$ is psychrometric coefficient $\left(0.062 \mathrm{kPa} \mathrm{C}^{-1}\right)$;

es-e is water vapor saturation pressure deficit $(\mathrm{kPa})$, and

$\Delta$ is the curve slope of the water vapor saturation pressure $\left(\mathrm{kPa}^{\circ} \mathrm{C}^{-1}\right)$ calculated by [eq. (2)].

$$
\left.\Delta=\frac{0.498 \times e s}{(T+273)^{2}}\right)
$$

where,

$\Delta$ is the curve slope of water vapor saturation pressure $\left(\mathrm{kPa}^{\circ} \mathrm{C}^{-1}\right)$;

es is vapor saturation pressure of water $(\mathrm{kPa})$, and

$\mathrm{T}$ is air temperature.

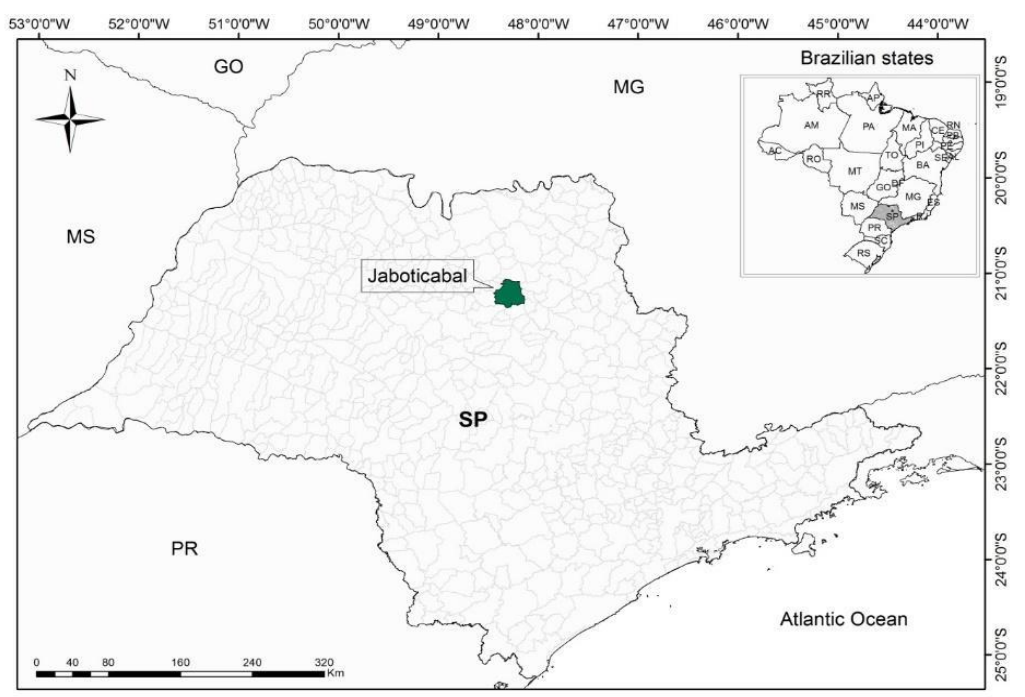

FIGURE 1. Geographical location of Jaboticabal region in the state of São Paulo, Brazil.

\section{Normalization}

To construct an artificial neural network, the data should be firstly normalized. This step aims to adapt input data to the dynamic range of neural network activation functions, which in this case are hyperbolic tangent (intermediate layer) and linear function (outer layer). As mentioned by Bishop (1995), the input data must be normalized because, if they differ by orders of magnitude, the network outputs cannot express their significance in the result. Data normalization process was performed according to [eq. (3)]:

$$
x^{*}=\frac{x_{0}}{\bar{x}+n_{s} s}
$$

where,

$X^{*}$ is the normalized variable;

$X_{0}$ is the original variable;

$X$ is the average obtained from samples to form the training set; 
$S$ is the standard deviation of original variables, also from the training set, and

$N_{S}$ is the number of standard deviations to be considered.

$\mathrm{N}_{\mathrm{S}}$ value was obtained empirically, respecting neural network dynamic range, which should contain the results found in $\mathrm{X}^{*}$ calculations. Normalization was applied initially to the training set and then extended to the testing set, using the same normalization factor (Nascimento et al., 2009).

Seasonality of climate variables must be taken into consideration. After normalization, data are seasonally adjusted to reveal residue of the series to be modeled, allowing hidden feature detection. When employing a neural model, Nelson et al. (1999) observed forecasts that are more accurate with seasonally adjusted data if compared to those collected without such pre-processing. Researchers as Calôba et al. (2002) performed deseasonalization of data through trend removal, and then withdrawal cycles.

To forecast reference evapotranspiration, we adopted a feed-forward Multi-Layer Perceptron (MLP), which is a traditional Artificial Neural Network. Numerous topologies and variations were tested between neurons in the intermediate and outer layers until the most accurate were obtained.

Neural network modeling consisted of preliminary analysis and identification of model type, network training and verifying, and process validation. Here, MLP learning was supervised, and algorithm learning was backpropagation for multilayer nets.

A simplified MPL-ANN typically has three stages: input, processing, and output (Figure 2). In this study, MLP was used to forecast the reference evapotranspiration for the next day $(\mathrm{ETP}+1)$ using air temperature data (from the previous day).

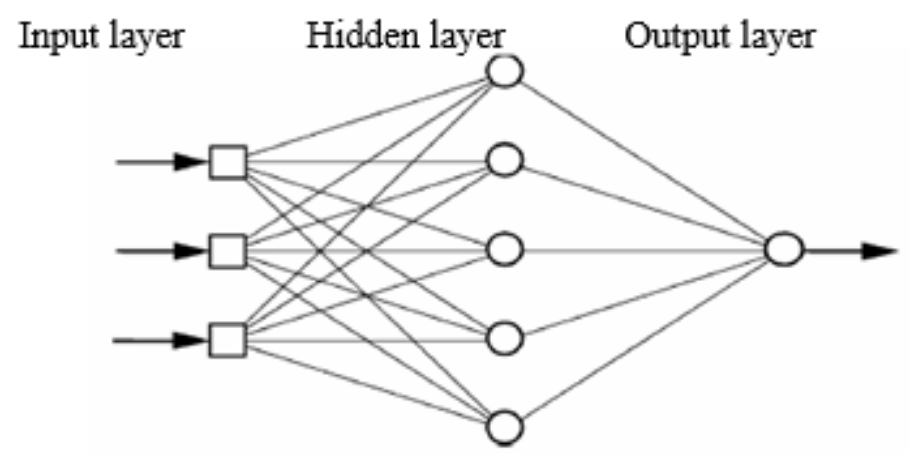

FIGURE 2. Simplified neural network Multilayer Perceptron (MLP).

Mathematically, one MLP with $\mathrm{N}$ layers, $\mathrm{H}$ hidden neurons, and an output neuron can be expressed by [eq. (4)]:

$$
\mathrm{Y}=\mathrm{S}_{\mathrm{k}}\left(\sum_{\mathrm{h}=1}^{\mathrm{H}} \mathrm{O}_{\mathrm{h}} \mathrm{W}_{\mathrm{h}} \mathrm{W}_{0}\right)
$$

where,

$\mathrm{Y}$ is the ANN output,

$\mathrm{O}_{\mathrm{h}}$ is an output value of the $\mathrm{h}^{\text {-th }}$ hidden neuron, being $\mathrm{O}_{\mathrm{h}}$ given by [eq. (5)].

$$
O_{h}=S_{k}\left(\sum_{h=1}^{H} X_{n} W_{n h} W_{0 h}\right)
$$

where,

$\mathrm{Xn}$ are the ANN inputs;

Wh and (Wnh) are the synaptic weights between the hidden neurons and the ANN outputs and inputs, respectively, and

$\mathrm{X} 0$ is $1, \mathrm{~W} 0$ and $\mathrm{W} 0 \mathrm{~h}$ are ANN training algorithm initial values. 
The activation function is the logistic sigmoid given by [eq. (6)]:

$$
S_{k}(x)=\frac{1}{1+e^{-x}}
$$

The criteria for assessing ANN performance were accuracy, precision, and trend. Accuracy was assessed by absolute percentage error (MAPE \%), precision by the adjusted determination coefficient $\left(\mathrm{R}^{2}\right)$, and trend by systematic error (in the same units as the original data) (Equations 7 and 9 , respectively).

$$
\begin{aligned}
& R^{2} \text { adjusted }=\left[1-\frac{\left(1-R^{2}\right) \times(n-1)}{n-k-1}\right] \\
& M A P E=\frac{\sum_{i=1}^{n}\left(\left|\frac{\text { Yest }_{i}-\text { Yobs }_{i}}{\text { Yobs }_{i}}\right| \times 100\right)}{n} \\
& E S=\sqrt{\frac{\sum_{i=1}^{N}\left(\text { Yobs }_{i}-\text { Yest }_{-C}\right)^{2}}{n}}
\end{aligned}
$$

where,

$\mathrm{R}^{2}$ is the determination coefficient $(\%)$;

$n$ is data number (years);

$k$ is the number of independent variables in the regression;

$\mathrm{Y}_{\text {esti }}$ is the estimated variable;

$\mathrm{Y}_{\mathrm{obsi}}$ is the observed variable, and

$\mathrm{Y}_{\text {est-C }}$ is the variable estimated by linear regression between the observed ( $\left.\mathrm{Y}_{\mathrm{obsi}}\right)$ and estimated (Yesti) variables.

To consider an ANN valid without rigging data and/or evidence of contradictory results, the data must be divided into sets, one for the training of neurons, and the other the testing of results. Thus, in this study, we separated $75 \%$ from data for network training (2002 to 2010) and $25 \%$ for testing (2011 to 2013).

The ANN setting was empirically determined. Initially, all seasons of the year were considered. However, as evapotranspiration prediction was based only on average temperature, and it varies largely throughout the four different seasons, training and MLP network testing were separated by season. Nevertheless, the separate training and testing processes do not minimize reference application since the final user (farmer) would only have to indicate year and temperature season to obtain an evapotranspiration prediction.

\section{Activation Function}

The basic function of an artificial neuron element, also known as a processor, is to perform the summation estimated by factors, known as the synaptic weights of input vectors, and to apply the result as input to a nonlinear function, i.e. activation function. Three activation function classes represented in figure $\mathrm{X}$ are usually employed:

1) Signal Function: for this type of function, there is:

$$
\begin{array}{r}
F(x)=1 \text { if } x>0 \\
0 \text { if } x \leq 0
\end{array}
$$

2) Linear Function by parts: for this function, there is: 


$$
\begin{aligned}
\mathrm{F}(\mathrm{x})= & 0 \text { if } \mathrm{x} \leq 0 \\
& \mathrm{x}+\mathrm{a} \text { if }-\mathrm{a}<\mathrm{x}<\mathrm{a} \\
& 1 \text { if } \mathrm{x} \geq \mathrm{a}
\end{aligned}
$$

3) Sigmoid function: is the activation function mostly used in artificial neural networks, defined as an increasing monotonic function with asymptotic and softness properties. An example of sigmoidal function is the logistic function, set by: $\mathrm{F}(\mathrm{x})=a \mathrm{x} \mathrm{e}-1+1$

Where: $a$ is the function slope parameter. In many cases, a sigmoid function output interestingly varies between -1 and 1 ; in these cases, a hyperbolic tangent function is applied, which is given by: $\mathrm{F}(\mathrm{x})=\operatorname{tgh} 2 \mathrm{x}=\mathrm{x}$

In this proposed model, the signal function was used in two layers (intermediate and outer). The air temperature was verified to be the only entrance. As this factor varies greatly among the four seasons, it was necessary to calibrate the separate network for each station to increase accuracy. The first intermediate layer, also called the hidden layer, encompassed 15 neurons for four seasons.

The number of neurons varied essentially in the second intermediate layer (Figure 3), which took 9 neurons in spring (Figure 3.a), 7 in summer (Figure 3b), 5 in autumn (Figure 3.c), and 9 in winter (Figure 3.d).
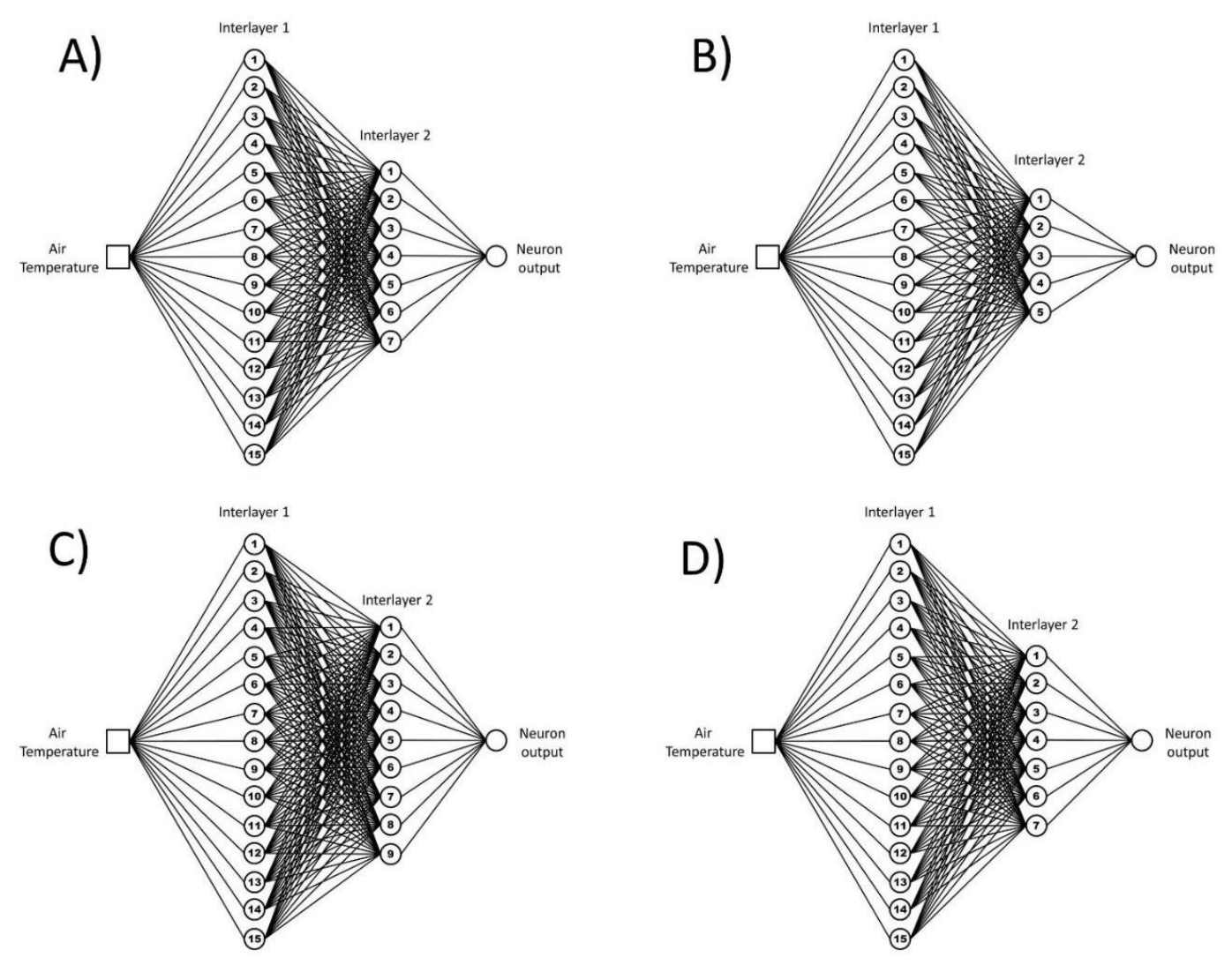

FIGURE 3. ANNs configuration for the summer seasons (a), spring (b), autumn (c) and winter (d).

To finish the topology setting, the second intermediate layer should be connected to a single MLP Neural Network output, with the changes already mentioned in each season (the four seasons have only one output), generating the evapotranspiration prediction.

\section{RESULTS AND DISCUSSION}

The air temperature varied from 21.8 to $26.5^{\circ} \mathrm{C}$, whereas reference evapotranspiration (RET) ranged from 3.6 to $5.8 \mathrm{~mm}$, for summer and winter seasons, respectively (Figure 4). 


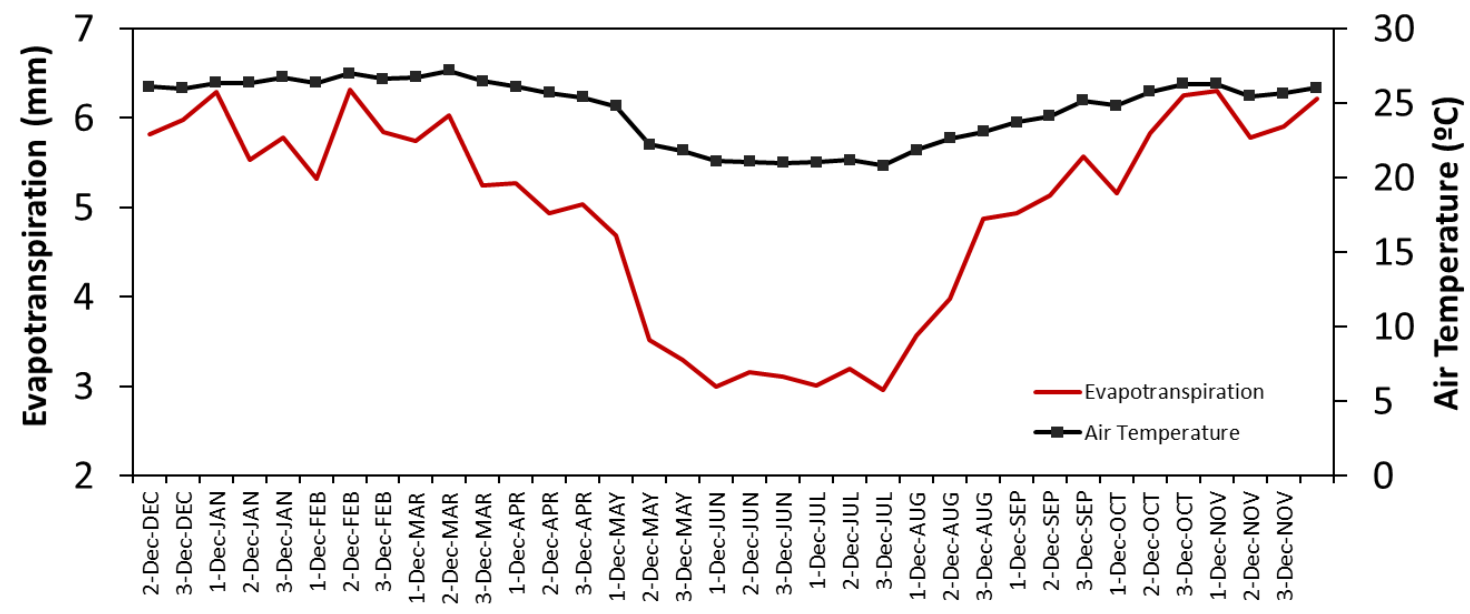

FIGURE 4. Reference Evapotranspiration $(\mathrm{mm})$ and air temperature $\left({ }^{\circ} \mathrm{C}\right)$ decennial averages of 2002 and 2010 for the region of Jaboticabal, SP.

The ANNs trained to predict the next-day $\mathrm{ET}_{0}(\mathrm{ET} 0+1)$ for the region of Jaboticabal were accurate since maximum MAPE was $12.67 \%$. The largest MAPEs in training and testing were observed in winter and the lowest in autumn. ANN calibrated for autumn season showed a MAPE of $9.01 \%, \mathrm{R}^{2}$ adj $=0.89$, and $\mathrm{ES}=5.62 \mathrm{~mm}$ in the training; and MAPE of $6.58 \%, \mathrm{R}^{2} \mathrm{adj}=0.94$, and Es $=3.14 \mathrm{~mm}$ in the testing (Table 1 ).

MAPE of $9.01 \%$ is noteworthy low because, in an average evapotranspiration of $6.0 \mathrm{~mm}^{\text {day }}$ 1 , it corresponds to a variation of only $\pm 0.54 \mathrm{~mm} \mathrm{day}^{-1}$. In a similar study, but performing estimation, Kumar et al. (2002) found an error lower than $0.3 \mathrm{~mm} \mathrm{day}^{-1} \mathrm{ET}_{0}$ when using ANNs. Trajkovic et al. (2003) reported it is possible to predict ET 0 by Penman-Monteith using ANNs. However, these authors used a large number of input variables such as air temperature, humidity relative, wind speed, and sunshine hours for the forecasting. The great advantage of the method proposed in this study is to get ET0+1 by Penman-Monteith, using only daily records of air temperatures.

TABLE 1. Accuracy (MAPE, mean absolute percentage error), accuracy $\left(\mathrm{R}^{2}\right.$ adj, determination coefficient) and trend (ES, systematic error) in the training and testing of reference evapotranspiration provided by ANN for the next day, for the summer seasons spring, fall and winter in the region of Jaboticabal, SP.

\begin{tabular}{lccccccc}
\hline Seasons & \multicolumn{2}{c}{ Training $(2002-2010)$} & & \multicolumn{3}{c}{ Test $(2011-2013)$} \\
\cline { 2 - 4 } \cline { 6 - 8 } & MAPE $(\%)$ & $\mathrm{R}^{2} \operatorname{adj}(\%)$ & ES & & MAPE (\%) & $\mathrm{R}^{2} \operatorname{adj}(\%)$ & ES \\
\hline Spring & 11.87 & 0.93 & 4.98 & & 10.14 & 0.96 & 4.78 \\
Summer & 10.82 & 0.92 & 5.91 & & 8.07 & 0.92 & 3.03 \\
Autumn & 9.01 & 0.89 & 5.62 & & 6.58 & 0.94 & 3.14 \\
Winter & 12.67 & 0.92 & 2.21 & & 12.13 & 0.95 & 1.53 \\
\hline
\end{tabular}

ANNs trained to perform ET0+1 prediction for summer, spring, autumn, and winter, in the region of Jaboticabal, disclosed the same number of neurons (15 neurons) in the first layer (Layer), while in the second layer, the number of neurons was different for each season (Table 2). Multiple layers use is necessary to enhance ANN ability in solving complex problems (non-linearly separable) since the Convergence Theorem of Perceptron (ANN with only one layer) has the capacity to solve only linearly separable problems (Minsky \& Papert, 1969). 
TABLE 2. Weights found in the training of artificial neural networks (ANN) to predict the reference evapotranspiration for summer, spring, fall and winter in the region of Jaboticabal, SP.

\begin{tabular}{|c|c|c|c|c|c|}
\hline \multicolumn{3}{|c|}{ Ideal Weights in ANN of Spring } & \multicolumn{3}{|c|}{ Ideal Weights in ANN of Summer } \\
\hline \multicolumn{2}{|c|}{ Layer $^{1}$} & Layer $^{2}$ & \multicolumn{2}{|c|}{ Layer $^{1}$} & Layer $^{2}$ \\
\hline $\mathrm{N}_{1}$ & 0.739557740 & $\mathrm{~N}_{1} \quad 0.359960170$ & $\mathrm{~N}_{1}$ & 0.554409264 & $\mathrm{~N}_{1} \quad 0.273879160$ \\
\hline $\mathrm{N}_{2}$ & 0.621621622 & $\mathrm{~N}_{2} \quad 0.156106855$ & $\mathrm{~N}_{2}$ & 0.316600877 & $\mathrm{~N}_{2} \quad 0.198932464$ \\
\hline $\mathrm{N}_{3}$ & 0.646191646 & $\mathrm{~N}_{3} \quad 0.563147120$ & $\mathrm{~N}_{3}$ & 0.592770881 & $\begin{array}{ll}\mathrm{N}_{3} & 0.147495271\end{array}$ \\
\hline $\mathrm{N}_{4}$ & 0.714987715 & $\mathrm{~N}_{4} \quad 0.622419010$ & $\mathrm{~N}_{4}$ & 0.491074771 & $\mathrm{~N}_{4} \quad 0.361478990$ \\
\hline $\mathrm{N}_{5}$ & 0.808353808 & $\mathrm{~N}_{5} \quad 0.828832063$ & $\mathrm{~N}_{5}$ & 0.653032134 & $\begin{array}{ll}\mathrm{N}_{5} & 0.479904980\end{array}$ \\
\hline $\mathrm{N}_{6}$ & 0.850122850 & $\mathrm{~N}_{6} \quad 0.815752367$ & $\mathrm{~N}_{6}$ & 0.440351209 & $\begin{array}{ll}\mathrm{N}_{6} & 0.416797463\end{array}$ \\
\hline $\mathrm{N}_{7}$ & 0.840294840 & $\mathrm{~N}_{7} \quad 0.553990763$ & $\mathrm{~N}_{7}$ & 0.427170478 & $\mathrm{~N}_{7} \quad 0.760425850$ \\
\hline $\mathrm{N}_{8}$ & 0.749385749 & $\mathrm{~N}_{8} \quad 0.658502106$ & $\mathrm{~N}_{8}$ & 0.574955286 & \\
\hline $\mathrm{N}_{9}$ & 0.754299754 & $\mathrm{~N}_{9} \quad 0.540275049$ & $\mathrm{~N}_{9}$ & 0.764127764 & \\
\hline $\mathrm{N}_{10}$ & 0.668304668 & & $\mathrm{~N}_{10}$ & 0.756756757 & \\
\hline $\mathrm{N}_{11}$ & 0.604422604 & & $\mathrm{~N}_{11}$ & 0.746928747 & \\
\hline $\mathrm{N}_{12}$ & 0.542997543 & & $\mathrm{~N}_{12}$ & 0.823095823 & \\
\hline $\mathrm{N}_{13}$ & 0.641277641 & & $\mathrm{~N}_{13}$ & 0.852579853 & \\
\hline $\mathrm{N}_{14}$ & 0.756756757 & & $\mathrm{~N}_{14}$ & 0.899262899 & \\
\hline $\mathrm{N}_{15}$ & 0.712530713 & & $\mathrm{~N}_{15}$ & 0.953316953 & \\
\hline \multicolumn{3}{|c|}{ Ideal Weights in ANN of Autumn } & \multicolumn{3}{|c|}{ Ideal Weights in ANN of Winter } \\
\hline \multicolumn{2}{|c|}{ Layer $^{1}$} & Layer $^{2}$ & \multicolumn{2}{|c|}{ Layer $^{1}$} & Layer $^{2}$ \\
\hline $\mathrm{N}_{1}$ & 0.798525799 & $\begin{array}{ll}\mathrm{N}^{1} & 0.808353808\end{array}$ & $\mathrm{~N}_{1}$ & 0.578137867 & $\mathrm{~N}_{1} \quad 0.796068796$ \\
\hline $\mathrm{N}_{2}$ & 0.791154791 & $\begin{array}{ll}\mathrm{N}_{2} & 0.869778870\end{array}$ & $\mathrm{~N}_{2}$ & 0.778567383 & $\mathrm{~N}_{2} \quad 0.840294840$ \\
\hline $\mathrm{N}_{3}$ & 0.751842752 & $\mathrm{~N}_{3} \quad 0.882063882$ & $\mathrm{~N}_{3}$ & 0.868991991 & $\mathrm{~N}_{3} \quad 0.742014742$ \\
\hline $\mathrm{N}_{4}$ & 0.761670762 & $\mathrm{~N}_{4} \quad 0.904176904$ & $\mathrm{~N}_{4}$ & 0.828263809 & $\mathrm{~N}_{4} \quad 0.840294840$ \\
\hline $\mathrm{N}_{5}$ & 0.820638821 & $\mathrm{~N}_{5} \quad 0.808353808$ & $\mathrm{~N}_{5}$ & 0.693855958 & $\begin{array}{ll}\mathrm{N}_{5} & 0.835380835\end{array}$ \\
\hline $\mathrm{N}_{6}$ & 0.835380835 & & $\mathrm{~N}_{6}$ & 0.750151195 & $\mathrm{~N}_{6} \quad 0.712530713$ \\
\hline $\mathrm{N}_{7}$ & 0.835380835 & & $\mathrm{~N}_{7}$ & 0.468336564 & $\mathrm{~N}_{7} \quad 0.729729730$ \\
\hline $\mathrm{N}_{8}$ & 0.796068796 & & $\mathrm{~N}_{8}$ & 0.731155985 & \\
\hline $\mathrm{N}_{9}$ & 0.842751843 & & $\mathrm{~N}_{9}$ & 0.804824739 & \\
\hline $\mathrm{N}_{10}$ & 0.796068796 & & $\mathrm{~N}_{10}$ & 0.786584101 & \\
\hline $\mathrm{N}_{11}$ & 0.783783784 & & $\mathrm{~N}_{11}$ & 0.756754841 & \\
\hline $\mathrm{N}_{12}$ & 0.72972973 & & $\mathrm{~N}_{12}$ & 0.867844985 & \\
\hline $\mathrm{N}_{13}$ & 0.810810811 & & $\mathrm{~N}_{13}$ & 0.682145627 & \\
\hline $\mathrm{N}_{14}$ & 0.874692875 & & $\mathrm{~N}_{14}$ & 0.566080528 & \\
\hline $\mathrm{N}_{15}$ & 0.845208845 & & $\mathrm{~N}_{15}$ & 0.427343501 & \\
\hline
\end{tabular}

Legend = Layer 1 is first layer of neurons, Layer 2 is second layer of neurons. 
ANNs trained in this study showed a good performance because the minimum R2adj was 0.93 (Figure 5.B) during ET0+1 predictions. In the seasonal analysis, accuracy was high for all seasons, as the minimum $\mathrm{R}^{2}$ was 0.925 in spring (Figure $5 \mathrm{~B}$ ). Moreira and Cecilio (2016) endorsed ANNs to estimate air temperature in the Northeast of Brazil and observed high-precision results.

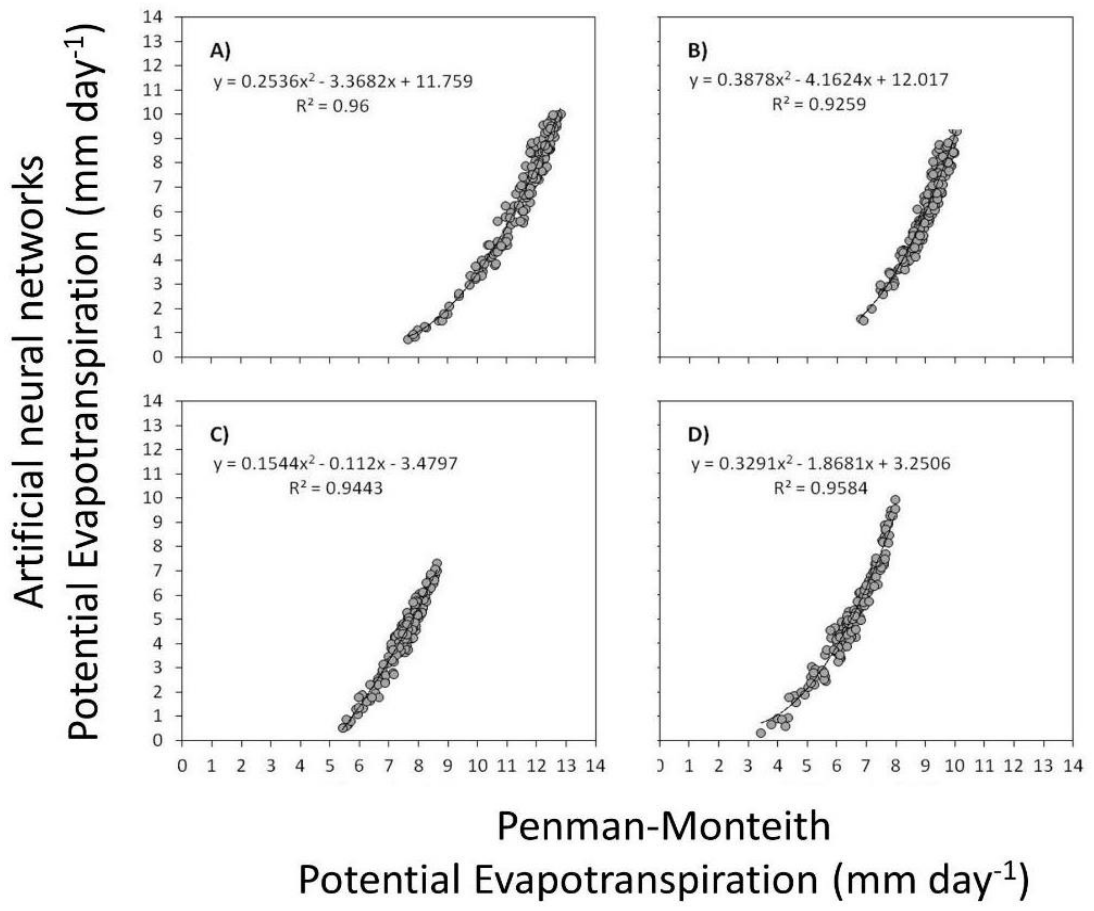

FIGURE 5. Performance of artificial neural networks (ANN) trained to predict the reference evapotranspiration for summer (a), spring (b), autumn (c) and winter (d) in the region of Jaboticabal, SP.

\section{CONCLUSIONS}

Reference evapotranspiration can be estimated with a day to spare at any time of the year by artificial neural networks, showing high accuracy and using only air temperature data as an input variable.

\section{REFERENCES}

Alvares CA, Stape JL, Sentelhas PC, Gonçalves JLM, Sparovek G (2014) Koppen's climate classification map for Brazil. Meteorologische Zeitschrif 22:711-728.

Aparecido LEO, Moreto VB, Souza Rolim Gde, Silva Cabral Moraes JRda, Valeriano TTB, Souza PS (2017a) Climatic potential for summer and winter wine production. Journal of Science of the Food and Agriculture 57(4):451-491. DOI: http://dx.doi.org/10.1002/jsfa.8575

Aparecido LEO, Rolim GS, Lamparelli R, Souza OS, Santos E (2017b) Agrometeorological models for forecasting coffea arabica yield. Agronomy Journal 109(1):249-258. DOI:

http://dx.doi.org/10.2134/agronj2016.03.0166

Allen RG, Pereira LS, Raes D, Smith M (1998) Crop evapotranspiration. Guidelines for computing crop water requirements. Rome, FAO Irrigation and Drainage (Paper n 56).

Allen RG, Pereira LS, Howell TA, Jensen ME (2011) Evapotranspiration information reporting: I. Factors governing measurement accuracy. Agricultural Water Management 98:899-920.

Back AJ (2007) Variação da evapotranspiração de referência calculada em diferentes intervalos de tempo. Engenharia Agrícola 27(1):139-145. 
Bishop CM (1995) Neural networks for pattern recognition. Oxford, Oxford University Press. 482p.

Calôba GM, Calôba LP, Saliby E (2002) Cooperação entre redes neurais artificiais e técnicas 'clássicas' para previsão de demanda de uma série de vendas de cerveja na Austrália. Pesquisa Operacional 22(3):345-358.

Carvalho DF, Rocha HS, Bonomo R, Souza AP (2015) Estimativa da evapotranspiração de referência a partir de dados meteorológicos limitados. Pesquisa Agropecuária Brasileira 50:1-11.

Dong B, Dai A (2016) The uncertainties and causes of the recent changes in global evapotranspiration from 1982 to 2010. Climate Dynamics:1-18.

Dutta B, Smith WN, Grant BB, Pattey E, Desjardins RL, Li C (2016) Model development in DNDC for the prediction of evapotranspiration and water use in temperate field cropping systems.

Environmental Modelling \& Software 80:9-25.

Feng X, Li Q, Zhu Y, Hou J, Jin L, Wang J (2015) Artificial neural networks forecasting of PM 2.5 pollution using air mass trajectory based geographic model and wavelet transformation. Atmospheric Environment 107:118-128.

Kim K, Yang Y, Lee J, Choi K, Kim T (1995) Classification of multispectral image using neural network. In: Procudings of IEEE International Geoscience and Remote Sensing Symposium (IGARSS) 2:446-448.

Kumar M, Bandyopadhyay A, Raghuwanshi NS, Singh R (2008) Comparative study of conventional and artificial neural network-based estimation models. Irrigation Science 26(6):531545 .

Kumar M, Raghuwanshi N, Singh R, Wallender W, Pruitt W (2002) Estimating Evapotranspiration using Artificial Neural Network. Journal of Irrigation and Drainage Engineering 128(4):224-233.

Liu H, Tian HQ, Li YF, Zhang L (2015) Comparison of four Adaboost algorithm based artificial neural networks in wind speed predictions. Energy Conversion and Management 92:67-81.

Minsky ML, Papert SA (1969) Perceptrons: an introduction to computational geometru. Cambridge, The MIT Press.

Nath S, Kotal SD, Kundu PK (2016) Seasonal prediction of tropical cyclone activity over the north Indian Ocean using three artificial neural networks. Meteorology and Atmospheric Physics:1-12.

Nascimento EM, Pereira BB, Seixas JM (2009) Redes Neurais Artificiais: Uma Aplicação no Estudo da Poluição Atmosférica e seus feitos Adversos à Saúde. Revista Brasileira de Biometria 27(1):37-50.

Raziei T, Pereira LS (2013) Estimation of ETo with Hargreaves-Samani and FAOPM temperature methods for a wide range of climates in Iran. Agricultural Water Management 121(4):1-18.

Sampaio G, Silva Dias P (2014) Evolução dos modelos climáticos e de previsão de tempo e clima. Revista USP (103):41-54.

Trajkovic S, Todorovic B, Stankovic M (2003) Forecasting of Reference Evapotranspiration by Artificial Neural Networks. Journal of Irrigation and Drainage Engineering 129(6):454-457.

Trajkovic S, Kolakovic S (2009) Evaluation of reference evapotranspiration equations under humid conditions. Water Resource Management 23(14):3057-3067.

Were K, Bui DT, Dick OB, Singh BR (2015) A comparative assessment of support vector regression, artificial neural networks, and random forests for predicting and mapping soil organic carbon stocks across an Afromontane landscape. Ecological Indicators 52:394-403.

Zanetti SS, Sousa EF, Oliveira VPS, Almeida FT, Bernardo S (2007) Estimating evapotranspiration using artificial neural network and minimum climatological data. Journal of Irrigation and Drainage Engineering 33(2):83-89. 